\author{
Г.М. Зельдович \\ Варшавский университет \\ (Польша, Варшава) \\ zeldowicz@yahoo.com
}

\title{
СПОСОБНОСТЬ МОДИФИЦИРОВАТЬ СОДЕРЖАНИЕ ПРЕДТЕКСТА КАК ПРИМЕТА ПЕРВОГО ДИСКУРСИВНОГО ПЛАНА В ЛИРИЧЕСКОМ ПРОИЗВЕДЕНИИ
}

В прототипическом случае лирический текст распадается на эмпирическую часть, где представлен какой-то переживаемый автором (точнее, лирическим героем) опыт, и фокус, т.е. часть, в которой автор приходит к тому или иному обобщению, открытию важной истины и/или в которой существенным образом изменяются его взаимоотношения с миром и/или с самим собой. Это ключевое для лирики композиционное противопоставление получает множество собственно лингвистических манифестаций, значительная часть которых связана с ощутимым повышением информативности в «итоговых» фрагментах. Одна из таких примет «итога» рассматривается в настоящей статье. Показано, что при прочих равных условиях лучшие шансы стать главным содержательным открытием имеет фрагмент, способный ретроспективно воздействовать на интерпретацию предтекста. Вынуждать переосмысление эмпирических фрагментов фокус может несколькими способами. Во-первых, он может в некотором плане обеднить их содержание, по сравнению с тем, какое мы были бы склонны им приписать в его отсутствие. Во-вторых, иногда фокус заставляет пересмотреть уже как будто присутствующие в более ранних частях текста смыслы, в частности сложившиеся там дискурсивные связи, и заменить их другими смыслами. В-третьих, бывает так, что в определенный момент своего развития лирический текст мог бы уже восприниматься как завершенный, однако к этому «как бы завершенному» фрагменту добавляется еще один, разрушающий возникшее представление о законченности - и он-то как раз и становится фокусным. В-четвертых, нередко случается, что если в развитии лирического текста просматривается та или иная общая тенденция, то именно фокус ее нарушит, тем самым переводя из ранга твердых правил в гораздо более низкий ранг статистического предпочтения.

Ключевые слова: лирика, композиция, фокус, первый дискурсивный план, лингвистические манифестации дискурсивной привилегированности, модификация содержания. 
Юрию Дерениковичу Апресяну -

с почтением и признательностью

\section{1. Предварительные замечания}

Среди важнейших исследовательских интересов юбиляра с давних времен были типология лингвистической информации и принципы, которые управляют взаимодействием отдельных присутствующих в высказывании смысловых компонентов. Смещая акценты в сторону лингвопоэтики, мы хотели бы на очень скромном материале показать, что в лирических стихотворениях нетривиальное типологическое обогащение выражаемых определенным фрагментом смыслов и одновременно особенное, тоже нетривиальное, взаимодействие этого фрагмента с иными фрагментами может становиться важным маркером композиционной структуры.

Известно, что в прототипическом случае лирический текст распадается на эмпирическую часть, где представлен какой-то переживаемый автором (или, точнее, лирическим героем - но здесь эта тонкость не слишком существенна) опыт, и часть, в которой автор приходит к тому или иному обобщению, открытию важной истины и/или в которой существенным образом изменяются его взаимоотношения с миром и/или с самим собой [см. особенно: Сильман 1977].

Очевидно, будучи предопределено самой природой жанра, именно это противопоставление является основным для лирического текста композиционным разломом, причем посвященные авторскому опыту эмпирические фрагменты и фрагменты, где совершается названное открытие (в дальнейшем именуем их фокусом), далеко не равноправны: первые содержательно подчинены вторым и уместны лишь в той степени, в какой эти вторые собой подготавливают, служат им своеобразной когнитивной опорой. Иными словами, эмпирические фрагменты формируют неглавный, или, если воспользоваться термином из нарратологии, «фоновый», план лирического дискурса, а главным планом являются фрагменты фокусные.

Как показывают проводимые нами исследования, оппозиция между эмпирическими частями текста и его фокусом получает вполне конкретные и достаточно последовательные лингвистические манифестации [см.: Зельдович 2015; 2016; 2018а; 2018б; Zeldowicz 2016]. Например, частыми отличительными особенностями фокуса являются богатство его дискурсивных связей с остальным текстом, его референциальная оторванность от иных, эмпирических фрагментов, определенного типа синтаксический параллелизм, особая целостность авторского сознания и т. д.

Глядя на это явление шире, можно предположить, что если не все, то весьма многие используемые при маркировании фокуса стратегии имеют общий знаменатель: коль скоро фокус обладает большей дискурсивной важностью, должна быть в общем случае более высокой и его информативность ${ }^{1}$. Разумеется, измерить и сопоставить информативность двух фрагментов текста в целом обычно либо очень

${ }^{1}$ В первом приближении эту информативность можно отождествить с тыняновской «теснотой» стихового ряда, но все-таки это не совсем одно и то же [см.: Зельдович 2018а]. 
трудно, либо и вовсе невозможно, однако может быть так, что один из фрагментов отчетливо более содержателен в каком-то отдельном и при этом когнитивно хорошо доступном, легко «вычленимом» аспекте своей смысловой структуры (или в нескольких таких аспектах).

К таким аспектам, разумеется, принадлежит типологическое богатство передаваемой соответствующим фрагментом информации. Действительно, в целом подобное богатство характерно для фокуса намного больше, нежели для эмпирических частей стихотворения [см.: Зельдович 2018а]. При этом, однако, в названной статье речь шла о богатстве, создаваемом в основном вполне «традиционными» типами информации, прежде всего прагматическими импликатурами. Здесь же мы хотим показать, что та же стратегия может осуществляться и иным, куда менее каноническим, но вместе с тем достаточно частым в реальных текстах способом.

\section{2. Гипотеза}

Допустим, читая в лирическом стихотворении некоторый фрагмент, мы построили его вполне удовлетворяющую нас (удовлетворяющую нашим ожиданиям относительно новизны, релевантности и пр.) интерпретацию, но за ним следует новый фрагмент, который эту интерпретацию настоятельно требует изменить. Безусловно, если последний, сверх того что он передает свой собственный смысл, еще и управляет интерпретацией другого, то при прочих равных условиях он окажется содержательно более богатым, притом более богатым не только в количественном, а и в определенном качественном плане, ибо данная информация, какое бы конкретное место мы ни отвели ей в нашем описании соответствующих текстов, очевидным образом не укладывается в традиционные типологические рамки. Следовательно, по логике наших рассуждений, у такого фрагмента есть больше шансов оказаться фокусом либо частью фокуса.

Вынуждать переосмысление эмпирических фрагментов фокус может несколькими способами. Во-первых, он может в некотором аспекте обеднить их содержание, по сравнению с тем, какое мы были бы склонны им приписать в его отсутствие; здесь преимущество фокуса по информативности оказывается связано сразу с двумя обстоятельствами: и с уменьшением содержательности эмпирических фрагментов как таковых, и со способностью фокуса их интерпретацией управлять, которая повышает его собственную содержательность. Во-вторых, иногда фокус заставляет нас пересмотреть уже как будто присутствующие в более ранних частях текста смыслы, в частности сложившиеся там дискурсивные связи, и заменить их другими смыслами. В-третьих, бывает так, что в определенный момент своего развития лирический текст мог бы уже восприниматься как завершенный (он содержательно самодостаточен, его структура уже соответствует жанровому канону, в частности переживаемый автором опыт уже привел его к открытию достаточно общей и важной истины, и т.д.), однако к этому «как бы завершенному» фрагменту добавляется еще один, разрушающий возникшее представление о законченности - и он-то как раз и становится фокусом либо наиболее важной 
частью в фокусе данного стихотворения. В-четвертых, нередко случается, что если в развитии лирического текста просматривается та или иная общая тенденция, то именно фокус ее нарушит, тем самым переводя из ранга твердых правил в гораздо более низкий ранг статистического предпочтения.

Ниже все эти возможности будут проиллюстрированы.

\section{1. Примеры 1-2}

Посмотрим сначала на случай, когда фокус своим содержанием как бы «разреживает» смысл эмпирической части, по сравнению с тем смыслом, какой можно было бы у нее усматривать при обычных условиях. Примером будет стихотворение японского поэта Т. Кито (XVIII в.; перевод А. Седых; здесь и ниже всюду, где речь идет о переводах иностранной поэзии, нас интересует именно русский текст):

Покашливая,

Выходит из дома старик.

Ворота открыть?

Ясно, что главная по смыслу строка здесь - последняя: именно она неожиданным образом вводит «прямо в суть» старости, в ее немощь и сопутствующее ей «мира обнищанье». Эта особенность последней строки имеет и непосредственно лингвистическую манифестацию.

Согласно хорошо известному прагматическому закону, если нам сообщают о некоторой ситуации и если это сделано обычным, конвенциональным способом, мы склонны предполагать, что соответствующие события происходят обычным образом, представлять себе наименее «маркированную», стереотипную их реализацию [см. особенно: Horn 1984; Levinson 2000].

Так, хотя фраза $Я$ порезал палец на семантическом уровне, на уровне собственно сказанного не уточняет, кому же палец принадлежал, интерпретируя ее, мы руководствуемся, во-первых, тем, что о порезанном пальце сказано самым простым и общепринятым способом (едва ли можно это сделать короче; едва ли можно найти более употребительные слова), во-вторых, тем, что, согласно нашим представлениям о мире, человек чаще всего режет свой собственный палец, — и поэтому приходим к выводу, что палец был пальцем самого говорящего.

Аналогичным образом в предложении Я был в кино с женой выбран, несомненно, наиболее привычный способ сообщить о соответствующем событии. Поэтому, хотя здесь не указывается прямо, что это была жена говорящего, такая интерпретация для нас все равно очевидна и среди возможных тут осмыслений наиболее привилегированна, попытка же ее «денонсировать» создает как минимум комический эффект (ср. Я был в кино с женой, причем со своей собственной), а нередко и аномалию (ср. диалог: - Я ходил в кино с женой. - Тогда почему домой тьл вернулся один? - ??Потому что это была не моя жена).

Подобное же «приведение к стереотипу» имеет место и в огромном числе менее очевидных случаев. Например, в норме наш обеденный стол стоит на ножках, так, 
что его столешница горизонтальна, а чайник мы ставим именно на нее. Поэтому фразу Я поставил чайник на стол крайне трудно отнести к ситуации, когда стол опрокинут набок, а чайник ставится на боковую поверхность ножки или на ребро столешницы, - притом что буквальному смыслу сказанного ('в результате действий говорящего чайник принял такое положение в пространстве, при котором он ориентирован вертикально и какая-то часть стола мешает силе тяготения каузировать падение чайника') такой вариант тоже вполне соответствует [см. подробнее: Herskovits 2009].

С другой стороны, поскольку смысл 'событие совершается стереотипным образом’ достраивается к буквальному смыслу сказанного путем прагматического вывода и является импликатурой, постольку в принципе он отменим: мы в общем случае вполне готовы от подобной инференции отказаться, если контекст прямо или косвенно ей противоречит ${ }^{2}$.

Вернемся теперь к стихотворению Т. Кито.

В принципе выйти из дома человек может и для того, чтобы уйти в другое, сравнительно удаленное место, и чтобы сделать что-то возле дома, и чтобы посмотреть, какая погода, не подъезжают ли гости и т. д. Однако в обычном случае, зная о чьемто выходе из дома и не зная других относящихся к делу обстоятельств, мы будем предполагать первый вариант: что данный человек собирается отойти от дома достаточно далеко. Эту импликатуру как раз и снимает последняя строка стихотворения: мир старика так сузился, что для него выход из дома стал чаще всего лишь выходом к воротам.

Если, как видим, первые две строки демонстративно лишаются «нормальной» для них импликатуры и обедняются в своем содержании и происходит так благодаря присутствию третьей строки, то в этой ее способности управлять интерепретацией остального текста вполне логично усмотреть примету ее фокусного статуса.

В более простой версии этот же прием можно найти и в немалом числе других японских хокку и танка, например в стихотворении Минамото-но Санэтомо (XIIХІІІ вв.; перевод В.С. Сановича):

${ }^{2}$ Напомним, что для П. Грайса отменимость импликатур была их дефиниционным свойством [см., например: Грайс 1985]. Позднее было признано существование «сильных», плохо или вовсе не отменимых импликатур, однако такой вариант надо признать особым и маркированным, ибо во всех подобных случаях неотменимость имеет свои посторонние и легко опознаваемые причины [см., например: Sperber, Wilson 1995; Carston 2002; Levinson 2000], в целом же импликатуры все-таки определенно тяготеют к отменимости. Что касается конкретного рассматриваемого тут типа импликатур, то «избавиться» от них бывает неодинаково легко, поскольку неодинаково прочны соответствующие стереотипы. Скажем, стереотип 'режут обычно свой палец' весьма тверд, поэтому текст ?'Я порезал палеu. То есть палеи соседа либо комичен, либо предельно неловок (лучше импликатуру 'это был мой палец’ тут вовсе не создавать, а сказать сразу Я порезал nалеи соседа). С другой стороны, стереотип 'разбивают чаще свою машину' явно слабее, явно более открыт для возможных исключений, поэтому текст Я разбил машину. Машину соседа уже достаточно приемлем. Обсуждать факторы, делающие такие импликатуры в большей или в меньшей степени отменимыми, мы не можем. Здесь важно лишь то, что в интересующем нас случае сама эта отменимость несомненна. 
Если б в нашем мире

Ничто не менялось вовек!

О, лодчонка на взморье!

Рыбак в ней правит веслом,

Второй — бечевой ее тянет.

Обычно, интерпретируя сообщения наподобие Ничто в доме не поменялось; Все в ней изменилось и т. п., мы отдаем себе отчет в том, что буквально они не могут быть истинными, и потому с помощью определенных прагматических процедур немедленно сужаем область действия квантификатора, так что смысл подобных фраз автоматически уточняется, конкретизируется до чего-то вроде 'в доме не поменялось ничто существенное'; 'в ней изменилось все существенное или многое из существенного'. Поэтому, например, высказывание Ничто в доме не поменялось в естественной речи вполне совместимо с допущением, что в доме подкрасили подоконник, починили карниз, что в доме появилась новая кошка и т. п. Иными словами, чисто логический смысл подобных предложений практически всегда дополнительно обогащается описанной импликатурой.

Того же типа импликатура должна возникать и тогда, когда мы читаем первые две строки рассматриваемой танка: они воспринимаются так, будто бы автор хочет, чтобы в мире не менялось нечто наиболее существенное. Однако в четвертой и пятой строках выясняется, что удержать от движения автор хотел бы даже то, что заведомо, с необходимостью подвижно и скоропреходяще, даже то, что в отказе от своей мимолетности, скорее всего, и не способно существовать. Таким образом разрушается часть предполагавшегося в строках 1-2 смысла, и это, вероятно, причина или одна из причин, почему две заключительные строки прочитываются тут как фокус.

\section{2. Пример 3}

Посмотрим на стихотворение Г. В. Иванова, где уже было сложившаяся интерпретация одного из фрагментов впоследствии существенно изменяется под влиянием фрагмента более позднего и фокусного:

1.

Остановиться на мгновенье, Взглянуть на Сену и дома, Испытывая вдохновенье, Почти сводящее с ума.

2.

Оно никак не воплотится, Но через годы и века Такой же луч зазолотится Сквозь гаснущие облака, 
3.

Сливая счастье и страданье

В неясной прелести земной...

И это будет оправданье

Всего, погубленного мной.

При первом чтении первой строфы мы склонны думать, что вдохновенье, о котором говорит автор, либо было испытано им лишь однажды, либо (это более вероятно) посещало его многократно, но здесь описывается в наглядно-примерном модусе, как выделенный из целого ряда сходных эпизодов единичный эпизод. Когда же в конце стихотворения автор упоминает о том, что́ им погублено, то подразумевается наиболее очевидным образом именно вдохновение, причем здесь из вдохновения, испытанного однажды или мыслимого как лишь однажды испытанное, оно практически наверняка становится «вдохновением вообще», некоей жизнеопределяющей всевременной ценностью.

Чтобы понять, насколько существен такой смысловой сдвиг, вспомним о важном разделении предикатов на предикаты «стадиального» и «индивидного» уровня (в английской традиции, соответственно, stage level predicates, individual level predicates [см.: Carlson 1980]; из более поздних работ на эту тему исключительно важна статья [Jaeger 2001]). Предикат стадиальный описывает ситуацию, которая приурочена к определенному месту и/или времени, а предикат индивидный характеризует главного участника ситуации на всем интервале его существования или, по крайней мере, на очень долгом подынтервале последнего; например, стадиальные предикаты выступают во фразах Маша сварила суп; Петя заболел, но индивидные - в: Маша - Петина сестра; Петя инженер; Петя высокий.

Разумеется, бывают случаи, когда один и тот же признак субъекта допустимо трактовать и как стадиально-преходящий, и как сверхдлительный («индивидный»). Скажем, если кто-то совершил ряд однотипных действий, то можно воспринять их как разрозненные, «стадиальные», но можно в их повторяемости увидеть и некую существенную, уже «индивидную», характеристику субъекта. Более того, подобного рода обобщение иногда способно строиться даже и на одном-единственном факте; например, говоря: Иван совершил однажды скверный поступок или Иван меня в жизни обманывал (неизвестно, сколько раз; возможно, что и лишь однократно), нередко подразумевают нечто вроде 'Иван (вообще) непорядочный человек', 'Иван (вообще) не заслуживает доверия'.

Тем не менее, как показано Г. Карлсоном, Г. Эйгером и многими другими авторами, разграничение между предикатами стадиального уровня и предикатами индивидными является лингвистически настолько основополагающим, что, если то или иное предложение и допускает двойственную интерпретацию, речь должна идти о полисемии, но ни в коем случае не о простой диффузности значения.

Поэтому когда у Г. В. Иванова вдохновение сначала выступает как некий частный эпизод или, может быть, ряд эпизодов в жизни автора, т.е. как сущность 
стадиального уровня, а затем отождествляется со всем авторским талантом и оказывается сущностью индивидной, с переходом этим сопряжена несомненная и существенная реинтерпретация соответствующих фрагментов текста - причем настоятельно требуют ее заключительные и вместе с тем фокусные тут строки.

\section{3. Пример 4}

Обратимся к восьмистишию М.И. Цветаевой:

1.

Дней сползающие слизни,

...Строк поденная швея...

Что до собственной мне жизни?

Не моя, раз не твоя.

2.

И до бед мне мало дела

Собственных... - Еда? Спанье?

Что до смертного мне тела?

Не мое, раз не твое.

Особенность этого стихотворения в том, что оно «двуфокусное»: ярко выраженными свойствами фокуса обладают здесь и четвертая, и восьмая строки. В частности, обе они заставляют определенным образом реинтерпретировать предшествующий им текст, а именно - сформированные в нем дискурсивные связи.

Действительно, в третьей строке то, что автору нет дела до собственной жизни, логично воспринимать как следствие из обстоятельств, которые даны в первой-второй строках: упрощенно говоря, однообразие жизни делает человека к ней равнодушным. Однако в строке 4 предъявляется уже совсем иная причина этого равнодушия, причем если бы мы попытались и сохранить первую причинно-следственную связь, и «достроить» к ней эту связь пояснительную, то должна возникнуть серьезная аномалия.

Как показано, среди прочих, Н. Эшером и А. Ласкаридес [Asher, Lascarides 2003], язык не позволяет, построив причинно-следственную дискурсивную связь между предшествующим предложением $\mathrm{P}_{1}$ и следующим предложением $\mathrm{P}_{2}$, позднее добавить к $\mathrm{P}_{2}$ предложение $\mathrm{P}_{3}$, вступающее с $\mathrm{P}_{2}$ в пояснительные отношения (т. е., проще говоря, указывающее на еще одну причину ситуации $\mathrm{P}_{2}$ ). Поэтому, например, интерпретируя текст $B$ комнате, где сидел Иван, вдруг запахло гарью. Он почувствовал себя не в своей тарелке. В комнату вошел ненавистный ему человек, как причину плохого самочувствия Ивана можно воспринять дурной запах, можно - появление ненавистного ему человека, но ни в коем случае - не то и другое вместе; ср. текст с иным порядком частей, где подобное уже допустимо, так как указание на обе потенциальные причины предшествует сообщению о плохом самочувствии Ивана: В комнате, где сидел Иван, вдруг запахло гарью. [Вдобавок] 
туда вошел ненавистный ему человек. Он почувствовал себя не в своей тарелке. Точно так же в тексте Было холодно. Маша простыла. Она промочила ноги как причину простуды позволительно трактовать либо холод, либо промоченные ноги, но не то и другое вместе - хотя такая интерпретация оказывается вполне естественной (пускай, конечно, и не единственно возможной) для текста Было холодно. Маша промочила ноги. Она простьла.

Поэтому в цветаевском стихотворении четвертая строка заставляет переосмыслить уже как будто сложившуюся причинно-следственную связь между первой-второй строками и третьей строкой (вероятно, третья строка должна восприниматься теперь как указание на причину, а не следствие того, о чем говорится в первой и второй, но это здесь не столь существенно).

Сходным образом устроена и вторая строфа. Риторические вопросы Eda? Cnaньe? естественно понять в отчасти презрительном (и, конечно, расширительном) смысле наподобие 'с телом не происходит ничего, что заслуживало бы интереса', и тогда вопросы эти должны хоть и не совсем прямым, но достаточно внятным образом указывать на причину того, о чем говорит седьмая строка, — на причину, почему автору безразлично собственное тело. Однако другую, еще более весомую причину этому предъявляет уже восьмая строка, и в силу описанной выше закономерности причинно-следственная дискурсивная связь между второй половиной шестой строки и седьмой строкой должна быть, фигурально выражаясь, денонсирована.

Как видим, дискурсивно первоплановый статус четвертой и восьмой строк сопрягается с их способностью управлять (ре)интерпретацией предшествующего текста.

\section{4. Пример 5}

Весьма схожий прием обнаруживается и в стихотворении О.Э. Мандельштама: 1.

После полуночи сердце ворует

Прямо из рук запрещенную тишь.

Тихо живет - хорошо озорует, Любишь — не любишь: ни с чем не сравнишь...

2.

Любишь - не любишь, поймешь - не поймаешь.

Не потому ль, как подкидыш, молчишь,

Что пополуночи сердце пирует,

Взяв на прикус серебристую мышь?

При первочтении строку 6, Не потому ль, как подкидыи, молчищь, более чем логично воспринять как находящуюся в причинно-следственной дискурсивной связи с предшествующими строками или, возможно, с одной только пятой строкой. 
Однако строки 7-8 недвусмысленно указывают на совсем другую причину, зная о которой, усматривать здесь названную связь уже никак нельзя ${ }^{3}$. Если причинноследственная связь тут и возможна, то устанавливаться она должна существенно по-иному, между предшествующими строками или, возможно, самой по себе пятой строкой и строками 6-8 как единым целым.

Таким образом, тут две заключительные и, несомненно, фокусные строки тоже обнаруживают способность принуждать к реинтерпретации предшествующего текста.

\section{5. Пример 6}

Более сложный пример подобной рекурсии находим у Г. В. Иванова:

1.

Теперь, когда я сгнил и черви обглодали

До блеска остов мой и удалились прочь,

Со мной случилось то, чего не ожидали

Ни те, кто мне вредил, ни кто хотел помочь.

2.

Любезные друзья, не стоил я презренья,

Прелестные враги, помочь вы не могли.

Мне исковеркал жизнь талант двойного зренья,

Но даже черви им, увы, пренебрегли.

Поначалу строки 5-6 воспринимаются так, будто в них делается определенный вывод из сказанного в строках 3-4: позднейшие события свидетельствуют, что друзьям автора не следовало его презирать, а врагам - пытаться оказать ему помощь.

Однако в свете двух заключительных и, безусловно, фокусных строк становится понятным, что строки 5-6 не только содержат это умозаключение, но в них еще и наглядно, в самой их парадоксальной, оксюморонной организации являет себя тот «талант двойного зренья», чье присутствие у автора будет прямо декларироваться в седьмой строке.

Особенно важно здесь то, что, если бы автор, сказав: Со мной случилось то, чего не ожидали / Ни те, кто мне вредил, ни кто хотел помочь, дальше никаким, хотя бы косвенным, образом не пояснил, что же именно случилось, возник бы ощутимый эффект недосказанности; поэтому такое сообщение заставляет нас ожидать, что следующее за ним будет его детализацией, будет более конкретно представлять существо случившегося.

${ }^{3}$ Очевидно, поскольку само понятие дискурсивной связи предполагает, что вступают в нее самостоятельные предикации, постольку названное указание, конечно, связано со строкой 6 уже не собственно дискурсивным, а семантико-синтаксическим отношением, но от этого существо дела не меняется. 
Разумеется, если в строках 5-6 авторское «двойное зренье» являет себя в самом способе их организации, это не значит, будто бы между ними и третьей-четвертой строками устанавливается детализационная дискурсивная связь. И тем не менее тут можно увидеть вполне распознаваемое ее подобие, причем подобие, возникающее только «с подсказки» двух заключительных, дискурсивно первоплановых строк.

\section{6. Пример 7}

Как мы говорили выше, иногда кажется, что лирический текст уже пришел к своему содержательному завершению, к открытию достаточно важной истины однако за как будто оканчивающим его фрагментом следует открытие истины еще более неожиданной, играющее роль подлинного фокуса и принуждающее прежнее представление о границах данного текста пересмотреть.

Примером будет стихотворение Ф. Пессоа (перевод с португальского наш. Г.3.):

1 .

Наедине, наедине

С моей тревогой неминучей,

Где нет на дне

Ни просветлений, ни созвучий...

2.

Я в ней исчезну,

Но эту боль не передам;

Она как бездна: видишь бездну -

И ничего не видишь там.

В каком-то смысле то, что тревога автора подобна бездне, уже объясняет ту ее невыразимость, мотив которой разрабатывался в первых шести строках, и потому начало седьмой строки с определенной долей правдоподобия могло бы восприниматься здесь как главный смысловой итог ${ }^{4}$. Тем не менее на этом текст не завершается, следом идет куда более ошеломительное обобщение, оказывающееся истинным фокусом и одновременно заставляющее подобную интерпретацию начисто отвергнуть.

\section{7. Пример 8}

Кажется, еще нагляднее описанный композиционный принцип обнаруживает себя в стихотворении А. Мачадо (перевод с испанского наш. - Г. 3.):

${ }^{4}$ Разумеется, этому препятствуют ритмико-метрические обстоятельства, но мы сейчас говорим только о содержании. 
Легко лететь, легко лететь, как птица:

Довольно оторваться от земли -

И не суметь на землю опуститься:

И ты летишь, и крылья понесли...

По своей и неожиданности, и обобщенности уже третья строка здесь вполне способна быть фокусом, однако за ней следует еще и четвертая, которая то удивительное, даже ошеломительное, о чем сказано в третьей, дополнительно вводит в более широкий ситуативный контекст - и тем самым делает его в нашем восприятии куда более правдоподобным. Иными словами, именно благодаря четвертой строке наша реакция на третью ощутимо сдвигается от изумления к принятию, а тем самым содержание третьей в своем модальном аспекте серьезно видоизменяется. Этим обстоятельством, по-видимому, объяснимо то, что как фокус тут воспринимается не только третья, откровенно «фантастическая», но также и заключительная, куда более предметная в своем содержании, строка и что она отнюдь не производит впечатления лишней, создающей просто ненужную длинноту.

\section{8. Пример 9}

Наконец, как мы уже говорили выше, присущая фокусу способность управлять восприятием предшествующего текста проявляется в том, что фокус может подчеркнуто нарушить некую сложившуюся в предтексте устойчивую и заметную инерцию, тем самым существенно изменяя ее статус, переводя ее из твердого правила в куда менее обязывающее статистическое предпочтение.

Присмотримся к тому, как строятся дискурсивные связи в четверостишии Омара Хайяма (перевод с фарси Г. Плисецкого):

Нет ни рая, ни ада, о сердце мое!

Нет из мрака возврата, о сердце мое!

И не надо надеяться, о мое сердце!

И бояться не надо, о сердце мое!

Вторая строка суть логический вывод из первой, точнее из содержащегося в ней смысла 'рая нет'. Третья - снова вывод, следствие из того, что сказано во второй. Таким образом, в первой-третьей строках уже формируется ощутимая инерция: всякая предшествующая и следующая строки находятся в причинно-следственной дискурсивной связи.

Четвертая строка эту инерцию ломает, ибо ее содержание хотя и входит тоже в причинно-следственную связь, но не с содержанием третьей или второй строки, а с содержанием первой, вдобавок еще и с той его частью 'ада нет', которая в прежних авторских рассуждениях практически полностью игнорировалась.

Поэтому дискурсивная связь с предтекстом у четвертой строки существенно иного характера, нежели между второй и третьей, причем перемена эта должна оказаться особенно ощутимой как раз на фоне того обстоятельства, что сам семантический тип связи тут не изменяется, но остается таким, каким был и прежде. 
Кажется убедительным заключить, что одной из примет фокусного статуса финальной строки здесь и является ее способность денонсировать возникшую ранее установку «текст развивается за счет того, что в каждом следующем предложении извлекается вывод из предыдущего».

\section{4. Статистические данные и выводы}

В начале статьи мы предположили, что достаточно частая примета фокуса состоит в его способности управлять интерпретацией более ранних фрагментов текста, вынуждая на такое их осмысление, которое иначе не возникало бы или оказалось бы маловероятным. Статистические данные, полученные нами при анализе материала, эту гипотезу подтверждают. Обследовав 200 лирических стихотворений, мы в семи рассмотренных выше случаях обнаружили подобное свойство у фокусной части текста и ни разу - у каких-либо эмпирических фрагментов.

Наиболее очевидное и уже представленное выше объяснение этому феномену заключается в том, что при прочих равных условиях способность модулировать восприятие иных частей текста обеспечивает соответствующему фрагменту даже не просто более высокую информативность, но, поскольку такая информация принадлежит весьма редкому, скорее почти не встречающемуся за пределами поэтической речи роду, обеспечивает передаваемым в этом фрагменте смыслам еще и особое типологическое разнообразие.

\section{Литература}

Грайс П. Логика и речевое общение // Новое в зарубежной лингвистике. 1985. Вып. 16. С. 217-237.

Зельдович Г.М. Об одном способе маркировать дискурсивную перспективу в лирической поэзии. Композиция и референциальные связи, или В чем неправы П. Хоппер и С. Томпсон // Linguistica Copernicana. 2015. № 12. С. 245-270.

Зельдович Г. М. «Золотое сечение» и композиция лирического текста // Wiener Slawistischer Almanach. 2016. Bd. 78. S. 95-148.

Зельдович Г. М. Композиция лирического стихотворения и «теснота» стихового ряда: Типологическое богатство информации как маркер первого дискурсивного плана в лирическом тексте // Людмила Савченко. Душа воспламененная : сб. науч. тр. / сост. Е. В. Маслий, А. В. Кардашова. Харьков : ХНУ им. В.Н. Каразина, 2018а. C. $287-346$.

Зельдович Г. М. Целостность авторского сознания как признак главного дискурсивного плана в лирическом стихотворении // Linguistica Copernicana. 2018б. № 15. C. 323-353.

Сильман Т. И. Заметки о лирике. Л. : Советский писатель, 1977. 224 с.

Asher N., Lascarides A. Logics of Conversation. Cambridge : Cambridge University Press, 2003. $552 \mathrm{p}$. 
Carlson G. N. Reference to Kinds in English. New York : Garland Publishing, 1980.311 p.

Carston R. Thoughts and Utterances. The Pragmatics of Explicit Communication. Oxford : Blackwell, 2002. $418 \mathrm{p}$.

Herskovits A. Language and Spatial Cognition. An Interdisciplinary Study of the Prepositions in English. Cambridge : Cambridge University Press, 2009. 220 p.

Horn L. Toward a new taxonomy for pragmatic inference: Q-based and R-based implicature // Meaning, Form, and Use in Context / ed. by D. Schiffrin. Washington : Georgetown University Press, 1984. P. 11-42.

Jaeger $G$. Topic-comment structure and the contrast between stage level and individual level predicates // Journal of Semantics. 2001. Vol. 18. P. 83-126.

Levinson S. Presumptive Meanings. Cambridge : MIT Press, 2000. 480 p.

Sperber D., Wilson D. Relevance: Communication and Cognition. $2^{\text {nd }}$ ed. Oxford : Blackwell, 1995. $326 \mathrm{p}$.

Zeldowicz G. Extraverted consciousness, introverted consciousness, and composition of lyrical discourse // Linguistica Copernicana. 2016. № 13. P. 301-318.

\author{
G. M. Zeldovich \\ Warsaw University \\ (Poland, Warsaw) \\ zeldowicz@yahoo.com
}

\title{
ABILITY OF MODIFYING THE MEANING OF EARLIER PARTS OF TEXT AS A PROPERTY OF FOREGROUND IN LYRICAL DISCOURSE
}

Prototypically, lyrical discourse comprises an empirical part, where some experience open to the author (lyrical hero) is presented, and a focal part, in which the author arrives at some generalization, discovery of a significant truth and/or changes her/his attitude towards the world and/or oneself. This basic compositional divide has a range of linguistic manifestations, many of which are related to increase of informativity in the 'wisdom' fragments. The paper is concerned with one such a manifestation consisting in that, other conditions being equal, better contenders for the focal role are those fragments capable of modifying the interpretation of the earlier ones. Such a modification may be realized through various mechanisms. First, the focus may somehow impoverish the meaning of the previous parts of the text, as compared to their most natural prima facie construal. Second, sometimes the focus calls for substitution of their interpretation with another one, e.g. such that implies different discourse links. Third, one may find lyrical texts that, at some point of their development, sound as fully competed, but then a new fragment is added; the latter one both destroys our previous expectations, and often turns out to be focal. Finally, in quite a few instances the development of the poem first strictly follows rule, but the focus departs from it, thus demoting it to the rank of a mere preference and also changing to some extent the meaning of what was said earlier. 
Key words: lyric poetry, composition, focus, foreground, linguistic manifestations of discourse salience, modification of meaning.

\section{References}

Asher N., Lascarides A. Logics of Conversation. Cambridge, Cambridge University Press, 2003. 552 p.

Carlson G. N. Reference to Kinds in English. New York, Garland Publishing, 1980. 311 p.

Carston R. Thoughts and Utterances. The Pragmatics of Explicit Communication. Oxford, Blackwell, 2002. 418 p.

Grais P. [Logic and conversation]. Novoe v zarubezhnoi lingvistike, 1985, vol. 16, pp. 217-237. (In Russ.)

Herskovits A. Language and Spatial Cognition. An Interdisciplinary Study of the Prepositions in English. Cambridge, Cambridge University Press, 2009. 220 p.

Horn L. Toward a new taxonomy for pragmatic inference: Q-based and R-based implicature. Meaning, Form, and Use in Context. D. Schiffrin (Ed.). Washington, Georgetown University Press, 1984, pp. 11-42.

Jaeger G. Topic-comment structure and the contrast between stage level and individual level predicates. Journal of Semantics, 2001, vol. 18, pp. 83-126.

Levinson S. Presumptive Meanings. Cambridge, MIT Press, 2000. 480 p.

Sil'man T. I. Zametki o lirike [Notes on lyrical poetry]. Leningrad, Sovetskii pisatel' Publ., 1977. 224 p.

Sperber D., Wilson D. Relevance: Communication and Cognition. $2^{\text {nd }}$ ed. Oxford, Blackwell, 1995. 326 p.

Zel'dovich G. M. [On one way of marking discourse perspective in lyrical poetry, or Where P. Hopper and S. Thompson go wrong]. Linguistica Copernicana, 2015, no. 12, pp. 245-270. (In Russ.)

Zel'dovich G. M. [The 'golden proportion' and composition of lyrical discourse]. Wiener Slawistischer Almanach, 2016, vol. 78, pp. 95-148. (In Russ.)

Zel'dovich G. M. [Composition of lyrical poem and 'density' of poetic range: Typological richness of information as marker of foreground in lyrical text]. Lyudmila Savchenko. Dusha vosplamenennaya [Lyudmila Savchenko. The ignited soul]. E. V. Maslii, A. V. Kardashova (Eds.). Kharkov, KharkovNational Univ. Publ., 2018a, pp. 287-346. (In Russ.)

Zel'dovich G. M. [Integrity of the author's conscience as marker of foreground in lyrical poem]. Linguistica Copernicana, 2018b, no. 15, pp. 323-353. (In Russ.)

Zeldowicz G. Extraverted consciousness, introverted consciousness, and composition of lyrical discourse. Linguistica Copernicana, 2016, no. 13, pp. 301-318. 